\title{
Disorganization and Financial Collapse
}

\author{
Dalia Marin* \\ Monika Schnitzer**
}

This version: October 1999

* University of Munich, Department of Economics, Ludwigstr. 28 Vgb, D-80539 Munich, Germany, and Centre for Economic Policy Research. Phone: +49 892180 2446, Fax: +49 892180 6227, e-mail: Dalia.Marin@1rz.uni-muenchen.de

** University of Munich, Department of Economics, Akademiestr. 1/III, D-80799 Munich, Germany, and Centre for Economic Policy Research. Phone: +49 892180 2217, Fax: +49 892180 2767, e-mail: schnitzer@lrz.uni-muenchen.de

This paper has been presented at the Fifth Nobel Symposium in Economics: The Economics of Transition, September 1999, Stockholm, at the University of Maryland, University of Basle, at the International Monetary Fund, at the 4th Annual International Conference on Transition Economics, Beijing, 1999, at the European Economic Association Meeting in Santiago de Compostela, September 1999, and at the Verein fr Socialpolitik in Mainz, October 1999. We would like to thank Daniel Kaufmann, Rachel Kranton, Holger Mller, Gerard Roland and the discussants and participants of the seminars and conferences for helpful comments, the Harvard Institute for International Development for financial and logistic support, Alexis Giesen and Bogdan Gorochowskij for valuable research assistance. 


\title{
Disorganization and Financial Collapse
}

\author{
This version: October 1999
}

\begin{abstract}
Recently, Blanchard and Kremer (BK) argued that disorganization has led to the output decline in the former Soviet Union. In this paper we introduce liquidity and credit constraints into the BK model and show how these problems can alleviate the hold-up problem. We argue further that barter creates a hostage which allows to deal with disorganization when credit enforcement is prohibitively costly. The theory helps to explain how the three observed phenomena of output decline, inter-firm arrears and barter in transition economies are connected. Based on a survey of 165 barter deals in the Ukraine in 1997, we reproduce the BK result with firm level and deal specific data and we show that in addition to the input shortage the financial shortage and barter have each an important effect on output growth.
\end{abstract}

Journal of Economic Literature Classification: G3, P3, D2, O1.

Keywords: Transition, financial crisis, output fall, credit constraint, barter, hold-up. 


\begin{abstract}
Recently, Blanchard and Kremer (BK) argued that disorganization has led to the output decline in the former Soviet Union. In this paper we introduce liquidity and credit constraints into the BK model and show how these problems can alleviate the hold-up problem. We argue further that barter creates a hostage which allows to deal with disorganization when credit enforcement is prohibitively costly. The theory helps to explain how the three observed phenomena of output decline, inter-firm arrears and barter in transition economies are connected. Based on a survey of 165 barter deals in the Ukraine in 1997, we reproduce the BK result with firm level and deal specific data and we show that in addition to the input shortage the financial shortage and barter have each an important effect on output growth.
\end{abstract}

Journal of Economic Literature Classification: G3, P3, D2, O1.

Keywords: Transition, financial crisis, output fall, credit constraint, barter, hold-up. 


\section{Introduction}

There are three dominant features which distinguish the development of the countries of the former Soviet Union from those of the early Transition Economies (TE) like Hungary, Poland, and the Czech Republic.

1. The decline in output has been much more pronounced in the former Soviet Union as compared to the early TE. In Russia, Belarus, and Ukraine, GDP for 1997 is estimated to stand at roughly half of its 1989 level. ${ }^{1}$

2. Inter-firm arrears are much larger and growing much faster in the Republics of the former Soviet Union as compared to the early TE (Rostowski, 1993).

3. Barter trade has become an important phenomenon in the domestic economy in Russia, Ukraine, Kasachstan, and Romania, while being absent in Central Europe. According to a recent survey in Russia, barter accounts for 60 percent of the economic activity in 1998. Our survey in the Ukraine gives an estimate of barter of 51 percent of total industrial sales in $1997 .^{2}$

These developments raise the question whether there is a connection between these three observations. More specifically, what is the relationship between the output decline and the inter-firm arrears on the one hand and inter-firm arrears and barter on the other? Has the presence of barter in the former Soviet Union and its absence in Central Europe something to do with the fact that inter-firm arrears are much larger and output declined much more sharply in the former Soviet Union?

In this paper we explore these questions based on a model which combines two arguments given in the transition literature for the output decline in transition economies. In a recent paper Blanchard and Kremer (BK) (1997) argue that the large decline in output in the former Soviet Union has been caused by "disorganization" and hold-up problems. Disorganization arises when old relationships break down before new ones can be established. In such a "no future" environment a typical mechanism to constrain

\footnotetext{
${ }^{1}$ See Transition Report 1998, Table 3.1, p. 50.

${ }^{2}$ See Commander and Mummsen (1998) for Russia and Marin, Kaufmann and Gorochowskij (1999) for the Ukraine.
} 
opportunistic behavior such as reputation does not work. Specificity in the relations between firms together with incompleteness of contracts results in disorganization in which intermediate producers in a chain of production refuse to deliver inputs which in turn leads to the collapse of output. ${ }^{3}$

Calvo and Coricelli (1995a,b) in turn have argued that the output losses in the early Transition Economies like Hungary, Poland, and the Czech Republic have been caused by a lack of credit. They suggest that inter-firm arrears in the early Transition Economies have been a response to the liquidity squeeze in the economy. Due to the lack of bank credits firms turn to trade credits from other firms to alleviate the financial squeeze.

In this paper, we combine the input shortage explanation of BK with the financial shortage explanation of Calvo and Coricelli to show that when both problems are present one can help with the other, rather than making things worse. More specifically, we introduce liquidity and credit constraints into the BK model and show how the credit constraint can alleviate the hold-up problem. The fact that the input seller has to make sure to get paid when the input purchaser is short of cash to pay for these inputs gives the input purchaser bargaining power. This bargaining power in turn reduces the possibility that the input supplier can exploit the input purchaser's need for the input. Our result that the lack of cash can alleviate the hold-up problem stands in contrast to BK's model who, if at all, see a positive role of cash as a commitment device to solve the coordination problem of firms.

We argue further that barter - a payment in goods rather than money - introduces a hostage, a commitment device which ensures debt repayment when credit enforcement is prohibitively costly, and by doing so it provides a mechanism to deal with disorganization when firms' creditworthiness problem is severe. This argument draws on ideas presented in earlier work on international countertrade by Marin and Schnitzer $(1995,1997)$, in which we show that international barter can be seen as an efficient institution to solve moral hazard problems which arise in the technology transfer to developing countries and in international trade which highly indebted countries. The contribution of the present paper is to point to the potential importance of the institution of barter in the context of transition. Barter trade is an inter-firm credit which is repaid in goods rather than

\footnotetext{
${ }^{3}$ A similar argument is made by Roland and Verdier (1999). In their model, output may fall because of market imperfections due to search frictions and Williamsonian relationship specific investments.
} 
money. Because goods are less anonymous than money, a claim on goods is easier to enforce than a claim on cash. Thus, barter can be used to collateralize a trade credit when firms' creditworthiness problem is severe and allows to finance business activities which otherwise would not take place. Through this credit channel barter helps to smoothen the output decline and thus prevents output from falling even further. ${ }^{4}$

Our theory helps to explain how the three observed phenomena of output decline, inter-firm arrears and barter, are connected. Based on a survey of 165 barter deals among firms in the Ukraine in 1997, we empirically reproduce the BK result with firm level data, and we show that in addition to the input shortage the financial shortage and barter have each an important effect on output growth. Finally, we show with deal-specific data how disorganization and the financial shortage affect the terms of trade in barter deals.

The paper is organized as follows. In section 2 we develop a chain of production model with credit constraints along the lines of BK (1997) and derive the conditions under which the credit constraint prevents the output from declining in the presence of the hold-up problem. In section 3 , we show that barter helps to maintain production when the credit problem becomes so severe that the input supplier refuses to deliver the input. In sections 4 and 5 we test the predictions of the model with firm and deal specific data of 165 barter deals which we have collected in the Ukraine in 1997. Section 6 concludes.

\section{A chain of production with liquidity constraints}

In this section we develop a chain of production model in the spirit of Blanchard and Kremer (1997). Similar to BK, we consider a good which requires $n$ steps of production. Each production step is carried out by a different firm. One unit of the input good gives, after $n$ steps of production, one unit of the final good. Each buyer along the chain can negotiate only with his supplier. This leads to $n$ bargaining problems along the chain. We assume Nash bargaining at each step with both parties equally sharing the joint surplus, whenever possible. The value of the final good is denoted by $v>0$. Intermediate goods $j$ produced at production step $j=1, \ldots, n-1$ have a value of $v_{j} \leq v$ if sold as input good for the next production step but they have a value of zero if sold to someone outside the

\footnotetext{
${ }^{4}$ For a survey of other explanations of barter in the former Soviet Union and their empirical validity see Marin, Kaufmann and Gorochowskij (1999).
} 
production chain. Within the production chain, the value of intermediate good $j, v_{j}$, is determined by the payment its producer $B_{j}$ receives when selling it to the next producer along the chain of production, $B_{j+1}$.

\section{Bargaining at each production step}

We now look at the production steps in more detail. Consider the parties involved in the first step of production, the supplier of the original input good, $S_{1}$, and the buyer, $B_{1}$. BK formulate the hold-up problem by assuming that $S_{1}$ cannot sign a contract with $B_{1}$ before he has produced the input. $S_{1}$ must first produce and only then - when the cost of producing is sunk - can bargain over the input price. In contrast to BK we consider a situation in which the supplier holds up the buyer rather than the other way round. We assume that $B_{1}$ needs to make a relationship specific investment $i$ at date 0.9 . This investment could be thought of as the time and money $B_{1}$ spends in order to find an adequate supplier and establish a business relationship. This formulation of the hold-up problem on the buyer's rather than the supplier's side seems to us to be more plausible in the context of the former Soviet Union, since input suppliers are on the short side of the market. Thus, it is the input buyer who has to spend time in order to find an adequate supplier. ${ }^{5}$ The problem is that at the time of this investment, the two firms cannot write a contract which commits $S_{1}$ to deliver the input good for a particular price in the future. This leads to a hold up problem in the bargaining of the price when the input good is actually delivered.

At date 1 , the two parties can negotiate about the delivery of $S_{1}$ 's input good and about the price. To save on notation we normalize $S_{1}$ 's opportunity cost of delivering the input to zero and we assume that $S_{1}$ delivers the input only if he expects a strictly positive surplus from the transaction. As specified above, $v_{1}$ denotes the value of the input good to $B_{1}$. This value is determined by the future bargainings and solved recursively below.

In contrast to $\mathrm{BK}$, we assume that $B_{1}$ cannot pay cash at the time of delivery because he is liquidity constrained. This assumption reflects a common problem in transition economies. In many countries of the former Soviet Union the liquidity squeeze has led to

\footnotetext{
${ }^{5}$ In section 5 we provide empirical evidence which supports the assumption that the hold-up problem is in fact on the buyer's side.
} 
the phenomenon of inter-firm arrears which accounts for more than 20 percent of GDP in Russia in 1997 (see for example Transition Report 1997, p.26). ${ }^{6}$ Thus, $S_{1}$ has to deliver the input good on a credit basis, if at all. $B_{1}$ will be able to pay when he is paid $v_{1}$ by the next buyer in the second production step. But of course, enforcing credit repayment in transition economies is notoriously difficult. We capture this notion by assuming that $S_{1}$ has to incur some (arbitrarily high) cost $x(p)$ to enforce repayment of $p$. This cost could be thought of as the cost of using the legal system, including lawyer fees and potentially bribes for judges or public authorities or the cost of private enforcement, including the use of Mafia etc. These costs are higher the less developed the legal system and the more indebted $B_{1}$. We assume for simplicity fixed enforcement cost $x\left(p_{1}\right) \equiv x .^{7}$

If $S_{1}$ has decided to deliver the input good at date $1, B_{1}$ can try to exploit the fact that credit enforcement is costly and default on some of his payment at date 1.1. Let $\tilde{p}_{1}$ denote the price paid by $B_{1}$ at this date. Figure 1 summarizes the time sequence of the bargaining at production step 1 .

\begin{tabular}{ccc}
0.9 & 1 & 1.1 \\
\hline $\begin{array}{c}B_{1} \text { makes } \\
\text { investment } i\end{array}$ & $\begin{array}{c}S_{1} \text { and } B_{1} \text { negotiate } \\
\text { price for input good, } p_{1}, \\
\text { input good delivered }\end{array}$ & $\begin{array}{c}\text { Payment of } \\
\text { input good }\end{array}$
\end{tabular}

\section{Figure 1: Time sequence at production step 1}

This first production step is repeated at steps 2 to $n$, with good 1 being used as an input good sold by $B_{1}$ (now called $S_{2}$ ) to $B_{2}$, and so on. Note that buyers $B_{2}$ up to $B_{n}$ may have to undertake a similar relationship specific investment $i_{j}, j=2, \ldots, n$, and may be similarly credit constrained as $B_{1}$. For notational convenience we restrict attention to investment levels $i_{j}, j=2, \ldots, n$, such that $i_{j} \leq i$ for all subsequent buyers. Similarly, the

\footnotetext{
${ }^{6}$ BK themselves report evidence based on a survey of 500 firms in Russia that the financial constraint was the most important shortage experienced by enterprises (see their Table IV). Between 1993 and 1995 over 60 percent of the firms experienced a shortage of financial resources compared with only over 20 percent of firms experiencing a shortage of materials.

${ }^{7}$ This allows us to solve the bargaining problem in each step of the production by simple analogy. It is straightforward to extend our analysis to enforcement costs that are increasing in the payment to be enforced. In this case, the problem of creditworthiness becomes more severe at later production steps which makes it more difficult to guarantee $S_{1}$ 's participation in the deal earlier on.
} 
enforcement costs $x$ are the same in all production steps (see Footnote 7 above).

When production is finished after $n$ steps and the value of the final good is realized, $B_{n}$ can use the revenues from selling this good to pay $\tilde{p}_{n-1}$, the price he actually pays after delivery of the intermediate good $n-1$. Similarly, when $S_{n}$ is paid, he can use his revenues for paying $S_{n-1}$ and so on. We assume that the maximum payment that can be enforced at each production step $j$ is equal to the revenues $v_{j}$ generated from selling the good to the next production step. ${ }^{8}$

\section{The credit problem and contract enforcement}

Let us now solve production step 1 recursively, taking as given the value of the good to be produced at this step, $v_{1}$. Recall that at date 1 , when $S_{1}$ delivers the input good, $B_{1}$ has no cash to pay for the input. At date 1.1, when realizing his profits from selling the input to the next buyer, $B_{1}$ has enough cash to pay but if he does not do so voluntarily $S_{1}$ 's has to incur costs $x$ if he wants to enforce payment of $p_{1}$. Suppose $B_{1}$ refuses to pay the full price $p_{1}$ on which the two parties agreed at date 1 , but offers to pay $\tilde{p}_{1}=p_{1}-x$ instead. If this happens, $S_{1}$ can either accept this payment or enforce $p_{1}$ at cost $x$. In equilibrium he will accept $B_{1}$ 's reduced payment.

At date 1 , the two parties have to agree on a price $p_{1}$. Since $B_{1}$ 's investment $i$ is already sunk at this date, this investment is not taken into account in the bargaining. This is what constitutes the hold-up problem of buyer $B_{1}$. However, the two parties anticipate at date 1 that $B_{1}$ will exploit his position after delivery of the input good and pay a reduced price at date 1.1. Recall that we have assumed Nash bargaining whenever possible. This implies that a price $p_{1}$ is chosen such that

$$
v_{1}-\left(p_{1}-x\right)=p_{1}-x \longleftrightarrow p_{1}=\frac{v_{1}}{2}+x
$$

i.e., in anticipating $B_{1}$ 's future price reduction, $S_{1}$ marks up $p_{1}$ in the first place, if this is possible.

\footnotetext{
${ }^{8} B_{j}$ might be involved in other production chains with revenues $v_{j}^{\prime}$. But we assume that $S_{j}$ has no knowledge about $B_{j}$ 's revenues outside this particular production chain and thus cannot use those revenues to enforce payment. Note, however, that this is without loss of generality. Allowing for higher enforceable payments leads only to level effects but does not affect the qualitative results of our model, as long as the maximum enforceable payment is finite.
} 
However, inflating the input price in anticipation of the price reduction at date 1.1 will not always be possible. $B_{1}$ 's liquidity constraint - the cash he gets when he himself sells the good to the next buyer, i.e. $v_{1}$ - puts a bound on the maximum payment that can be enforced at cost $x$. Thus, in order to fully capture the subsequent price reduction $S_{1}$ may want to inflate the price more than can credibly be enforced as payment at date 1.1 since, even at $\operatorname{cost} x, B_{1}$ cannot be forced to pay more than he has in his pockets at date 1.1. Thus,

$$
p_{1}=\min \left[\frac{v_{1}}{2}+x ; v_{1}\right]
$$

Only if enforcement costs are low, i.e. $x<v_{1} / 2$, will $S_{1}$ be able to pass on $x$ in the price mark-up. In this case, the fact that $B_{1}$ is liquidity constrained does not prevent $S_{1}$ 's and $B_{1}$ 's equally sharing the surplus, $v_{1}$. If $x$ is sufficiently large, i.e. $x>v_{1} / 2, B_{1}$ 's liquidity constraint will make it impossible for $S_{1}$ to pass on these costs to him. $B_{1}$ 's cash from the sale to the next buyer will simply not be enough to fully cover these costs. In this case, $B_{1}$ can exploit the fact that he is liquidity constrained to capture more than half of the surplus. If the enforcement cost excede the total value of the transaction, i.e. $x \geq v_{1}$, then $B_{1}$ captures the entire surplus and $S_{1}$ cannot guarantee himself a positive payoff. The following payoff functions summarize these three cases. If $S_{1}$ delivers the input good, then for a given $v_{1}$, the payoff of $B_{1}$ is

$$
\Pi_{B}^{1}= \begin{cases}\frac{v_{1}}{2}-i & \text { if } x \leq \frac{v_{1}}{2} \\ x-i \geq \frac{v_{1}}{2}-i & \text { if } \frac{v_{1}}{2} \leq x \leq v_{1} \\ v_{1}-i & \text { if } x>v_{1}\end{cases}
$$

Similarly, the payoff of $S_{1}$ is given by

$$
\Pi_{S}^{1}= \begin{cases}\frac{v_{1}}{2} & \text { if } x<\frac{v_{1}}{2} \\ v_{1}-x<\frac{v_{1}}{2} & \text { if } \frac{v_{1}}{2} \leq x \leq v_{1} \\ 0 & \text { if } x>v_{1}\end{cases}
$$

Thus, $B_{1}$ 's liquidity constraint gives him some bargaining advantage because credit enforcement is not costless to $S_{1}$ and the maximum payment that can be enforced is finite. If credit enforcement is a sufficiently severe problem, $B_{1}$ can use his bargaining power to shift the surplus in his favor. Otherwise, the bargaining is either not affected by the presence of enforcement costs (when $x$ is low) or $S_{1}$ refuses to participate in the deal (when $x$ is very large).

So far we have taken the value of the first production step, $v_{1}$, as given. We still have to determine how $v_{1}$ is affected by the value of the final product, $v$, by the number 
of production stepts, $n$, and by the fact that all buyers are liquidity constrained and that credit enforcement is costly. For this purpose, we have to solve the game recursively. The following Lemma characterizes $v_{1}$ as a function of $v, n$ and $x$.

Lemma 1 The value of production at step 1 is

$$
\begin{aligned}
& v_{1}(x, n, v)=\frac{v}{2^{n-1}} \quad \text { if } \quad x<\frac{v}{2^{n-1}} \\
& v_{1}(x, n, v)<\frac{v}{2^{n-1}} \quad \text { if } \quad x \geq \frac{v}{2^{n-1}}
\end{aligned}
$$

Proof: See Appendix

The important thing to note here is that if $x$ is small enough it does not affect the value of production at step 1 . The reason is that in all subsequent production steps $x$ can be fully covered by a price mark-up and hence does not affect the equal sharing of the surplus.

\section{Disorganization, financial constraint and output fall}

We can now state the conditions under which production takes place at the first and all subsequent production steps. $S_{1}$ agrees to deliver the input good at date 1 on a credit basis if and only if $\Pi_{S}^{1}>0$. This is the case if and only if

$$
\frac{v}{2^{n-1}}>x
$$

because in this case $v_{1}=v / 2^{n-1}$ by Lemma 1 and $x<v_{1}$, so that $\Pi_{S}^{1}=v_{1}-x>0$ (see equation (4)). If $x \geq v / 2^{n-1}$ instead, then $v_{1}<v / 2^{n-1}$ and hence $x>v_{1}$, so that $\Pi_{S}^{1}=0$ (see equation (4)).

At date $0, B_{1}$ is willing to engage in the up-front investment $i$ if and only if (6) is satisfied and in addition

$$
i \leq \max \left[x ; \frac{v}{2^{n}}\right]
$$

Note that $B_{1}$ 's payoff is $v / 2^{n}-i$ if $x<v / 2^{n}$, following from Lemma 1 and equation (3), and it is $x-i$ if $v / 2^{n}<x<v / 2^{n-1}$.

The following proposition states under which conditions production will take place in the presence of both the hold-up problem and the credit problem. 
Proposition 1 (i) Suppose there exists a hold-up problem, but no credit problem, i.e. $i>0$ and $x=0$. Then production takes place if and only if

$$
\frac{v}{2^{n}}>i
$$

(ii) Suppose there exists a credit problem but no hold-up problem, i.e. $i=0$ and $x>0$. Then production takes place if and only if

$$
\frac{v}{2^{n-1}}>x
$$

(iii) Suppose there exist both a hold-up problem and a credit problem, i.e. $i>0$ and $x>0$.

- If $x \leq \frac{v}{2^{n}}$ then production takes place if and only if

$$
\frac{v}{2^{n}} \geq i
$$

- If $\frac{v}{2^{n}}<x<\frac{v}{2^{n-1}}$ then production takes place if and only if

$$
x \geq i
$$

- If $\frac{v}{2^{n-1}}<x$ then no production takes place.

Proof: See Appendix

The first part of this proposition restates the BK result which says that production will take place when $B_{1}$ 's share of the value of production suffices to cover $B_{1}$ 's investment costs. Thus, the larger the number of production steps $n$, the smaller $B_{1}$ 's share of the value of production and thus the more severe the hold-up problem. The second part of the proposition makes Calvo and Coricelli's point that production might not take place due to the lack of credit even in the absence of the hold-up problem. Output collapses when $S_{1}$ 's share of the value of production does not suffice to cover $S_{1}$ 's enforcement costs. Thus, the larger the number of production steps $n$, the smaller $S_{1}$ 's share of the value of production and thus the less attractive it is for $S_{1}$ to grant a credit to $B_{1}$.

The last part of the proposition is particularly interesting. It shows that the presence of a liquidity and credit constraint can alleviate $B_{1}$ 's hold-up problem. This is the case if and only if

$$
\frac{v}{2^{n}}<i \leq x<\frac{v}{2^{n-1}}
$$


Without a liquidity constraint and enforcement costs, $B_{1}$ 's payoff would be $v / 2^{n}$, i.e. half the value of production at the first production step, and if $i>v / 2^{n}$ then no production would take place at all. However, if enforcement costs are sufficiently high, $B_{1}$ can exploit this fact to capture more than one half of the production value. $B_{1}$ 's ex-post bargaining power has to be sufficiently large to cover his ex-ante investment; i.e. $i \leq x$ in order for production to take place. Since $S_{1}$ needs a positive payoff, enforcement costs may not be too high, either; i.e. $x<v / 2^{n-1}$. Thus, production takes place if $i \leq x<v / 2^{n-1}$.

\section{Creating a hostage}

As we have seen, $S_{1}$ may not be willing to deliver the input good if the credit problem is too severe, i.e. if $x \geq v / 2^{n-1}$. Thus, if the buyer has no cash and the legal system to enforce payment is poorly developed a potentially valuable transaction does not take place. In this section we investigate to what extent barter can help under these circumstances. We will show that barter can be used as a hostage, i.e. as a commitment device that prevents the buyer from fully exploiting his bargaining power due to the enforcement cost. In this sense barter creates a deal-specific collateral that helps to alleviate the hold-up problem when credit enforcement is prohibitively costly. ${ }^{9}$

Suppose $B_{1}$ can produce one unit of a barter good, but only after date $1 .^{10}$ Let $w$ denote the value of the barter good and let $k$ denote $B_{1}$ 's production cost. If $B_{1}$ sells this barter good to someone outside the production chain he does so at a cash price $p_{B}^{C}=\frac{w+k}{2}$, assuming again Nash bargaining. This would give $B_{1}$ a payoff of $(w-k) / 2$. However, $B_{1}$ can also use this barter good as a hostage to improve his creditworthiness. In this case, $B_{1}$ promises to deliver the barter good to $S_{1}$ when credit repayment is due. The price for this barter good, $p_{B}$, is fixed together with $p_{1}$ before $S_{1}$ decides about his input delivery.

Of course, given that the two parties engage in Nash bargaining whenever possible they negotiate prices $p_{1}$ and $p_{B}$ such that they split the surplus of both transactions

\footnotetext{
${ }^{9}$ There is a related literature on barter in market economies which offers a different type of reasons for non-monetary trade. Prendergast and Stole (1997) consider barter as a way of segmenting the market on the basis of buyers ability to pay and Ellingson (1998) sees barter as a mechanism to reveal credibly that the debtor has no cash.

${ }^{10}$ If $B_{1}$ could deliver the barter good right away he would not be liquidity constrained because he could use the barter good as payment in kind.
} 
equally, taking into account the renegotiation on $p_{1}$ at date 1.1. This means that $p_{1}$ and $p_{B}$ have to be fixed such that

$$
\left(p_{1}-x\right)+w-p_{B}=v_{1}-\left(p_{1}-x\right)+p_{B}-k
$$

where the left hand side represents $S_{1}$ 's payoff and the right hand side $B_{1}$ 's payoff from carrying out both transactions. Solving this equation for $p_{1}$ leads to

$$
p_{1}=\frac{v_{1}}{2}+x-\left(\frac{w+k}{2}-p_{B}\right)=\frac{v_{1}}{2}+x-\left(p_{B}^{C}-p_{B}\right),
$$

where $p_{B}^{C}=\frac{w+k}{2}$ is the price for the barter good in a cash transaction, as argued above. Recall that the price $p_{1}$ that can be enforced is bounded above by $v_{1}$. Thus, for $x>v_{1} / 2$, i.e. when enforcement cost prevent an equal split of the surplus in the input trade, an increase in $x$ must be compensated by a reduction in $(w+k) / 2-p_{B}$ to induce the Nash bargaining solution. What this effectively means is that the inclusion of the barter trade allows $B_{1}$ to shift some of the profit back to $S_{1}$ by discounting the price of the barter $\operatorname{good} p_{B}$ by an amount of $p_{B}^{C}-p_{B}$.

Note, however, that $p_{B}$ cannot be chosen arbitrarily small because $B_{1}$ cannot be forced to deliver the barter good as promised, but has to be induced to do so voluntarily. If $B_{1}$ cheats on $S_{1}$ and refuses to deliver, all $S_{1}$ can do, given that $B_{1}$ has signed a contract that promises delivery of the barter good, is to try to prevent a sale of the barter good to someone else. We assume that $S_{1}$ succeeds with such an attempt with probability $(1-\pi)$ which reduces $B_{1}$ 's potential payoff from selling the barter good to $\pi \frac{w-k}{2}$, where $\pi \leq 1$. This implies that $B_{1}$ voluntarily delivers the barter good if and only if

$$
p_{B}-k \geq \pi \frac{w-k}{2}
$$

i.e. his payoff from delivering the barter good to $S_{1}$ must be at least as high as his payoff from trying to sell it to someone else.

Rearranging this expression leads to

$$
\left(\frac{w+k}{2}-p_{B}\right) \leq(1-\pi) \frac{w-k}{2} \equiv z,
$$

i.e., $B_{1}$ will discount the price for the barter good by an amount which equals at most what $S_{1}$ can take away from him due to the fact that $B_{1}$ has signed the barter contract. 
Using (16) in (14) we see that this constraint puts a lower bound on the mark-up for price $p_{1}$, if the surplus is to be split equally, i.e.

$$
p_{1} \geq \frac{v_{1}}{2}+x-z .
$$

We can interprete $z$ as the commitment value or hostage created by the barter contract. The larger this value $z$, the less the credit enforcement cost negatively affects $S_{1}$ 's willingness to participate in this input deal.

Considering now $B_{1}$ 's decision at date 0 , under what conditions will he be willing to make investment $i$ in the relationship with $S_{1}$ ? Note that the alternative to investing $i$ and carry out both the production of good 1 and the barter good is to produce only the barter good and sell it for price $p_{B}^{C}=(w+k) / 2$. This implies $B_{1}$ will undertake the investment if and only if the prices $p_{B}$ and $p_{1}$ chosen at date 1 are such that

$$
v_{1}-\left(p_{1}-x\right)+p_{B}-k-i \geq \frac{w+k}{2}-k
$$

The following proposition characterizes how barter affects the production decision.

Proposition 2 Suppose there exists a hold-up problem and a credit problem. Suppose further that $S_{1}$ and $B_{1}$ can use barter to create a hostage of a given size $z$, where $z \equiv$ $\frac{w-k}{2}(1-\pi)$

- If $x-z \leq \frac{v}{2^{n}}$ then production takes place if and only if

$$
\frac{v}{2^{n}} \geq i
$$

- If $\frac{v}{2^{n}}<x-z<\frac{v}{2^{n-1}}$ then production takes place if and only if

$$
x-z \geq i
$$

- If $\frac{v}{2^{n-1}}<x-z$ then no production takes place.

Proof: See Appendix.

Note first that the size of the hostage $z$ created by barter depends on two things. First, it depends on the value of the good offered as a means of payment in barter. 
When sold on the market outside of barter, this value is $(w-k) / 2$ for the buyer (always assuming Nash bargaining). Second, the size of $z$ depends on $B_{1}$ 's payoff when signing the barter contract and defaulting on payment which is expressed by $\pi(w-k) / 2$. The difference between these two payoffs is determined by the parameter $\pi$ and captures the commitment value which $B_{1}$ achieves by agreeing to repay the trade credit with goods rather than cash. By doing so $B_{1}$ reduces his chances to sell the barter good to someone else than $S_{1}$. $(1-\pi)$ is the probability of being caught when $B_{1}$ cheats on repayment and sells the barter good to someone else than $S_{1}$. The parameter $\pi$ can be thought of as a measure of how well the input seller can label the barter good as belonging to him. The smaller $\pi$, the less "anonymous" the barter good and the smaller $B_{1}$ 's cheating surplus from defaulting on payment. Thus, the smaller $\pi$, the larger the commitment value of barter and the larger the hostage $z \cdot{ }^{11} B_{1}$ uses the barter contract as a commitment to give $S_{1}$ more than half of the value of the barter transaction, as a compensation for the fact that $S_{1}$ 's payoff in the input transaction is too low due to credit enforcement cost. As a consequence, barter reduces the creditworthiness problem caused by the enforcement $\operatorname{costs} x$. This is reflected in the proposition by a shift of the parameter range for which the input transaction takes place. The benchmark is no longer $x$ but $x-z$.

\section{Evidence on output decline from firm level data}

In this section we explore the predictions from our model with data of 165 barter deals in the Ukraine in 1997.

The Appendix shows summary statistics of the variables used. We interviewed 55 firms to obtain information on 165 barter deals. Each firm provided us with 3 barter deals. Each barter deal involved 2 firms, the seller and the buyer. Many of the firms were well informed about the financial and economic conditions of the firms they traded with because they served as financiers. This is why we could obtain data on more than the 55

\footnotetext{
${ }^{11}$ See Marin and Schnitzer (1997) who discuss the property of anonymity of the barter good in the context of a theory of money. Note that the mechanism by which a hostage is created here differs from the one described in Marin and Schnitzer (1995). Here a hostage to control the credit enforcement problem is created when the buyer agrees to repay the loan in goods rather than money. There a hostage to control the technology transfer problem is created when the technology buyer in the developing country has not enough cash in his pocket and thus is unable to produce the good when the seller in the industrial country offers inferior technology.
} 
interviewed firms. Thus, depending on the variable, the firm information in our sample varies between 69 and 160 observations.

Our model implies, similar to BK that firms with more complex production will experience a more pronounced output loss. This can be seen by considering conditions (8), (10) and (11). The model implies further that the output decline will be less pronounced for firms short of cash. If firms are short of cash, they can use the credit constraint in the bargaining to prevent to be held up by the input supplier. However, if the financial constraint becomes too large it may be too costly for the supplier to enforce payment and thus he may not be willing to deliver the input good. The condition for the credit problem to alleviate the hold-problem given in equation (12) states that credit enforcement costs have to be just right. They have to be sufficiently high to give the input purchaser sufficient bargaining power to allow him to cover his ex-ante investment, but they may not be too high, otherwise the input supplier will refuse to participate in the deal. Thus, we expect an inversely U-shaped relationship between financial constraints and output growth.

The model implies also that the financial constraint should be less binding for bartering firms. Again, we expect an inversely U-shaped relationship between barter and output. If the financial constraint is too severe for the input supplier to participate in the deal, barter contributes to maintaining production by relaxing this constraint. However, when the barter exposure becomes large it might reduce the credit problem by so much that the input purchaser fails to be effective in capturing some of the rents from the input supplier and thus may not prevent the input purchaser from being held up. ${ }^{12}$

In Table 1 we take a first look at the relationship between the output growth of the firm, the liquidity squeeze and barter. We ask the question whether firms with large firm arrears, total arrears and with a big exposure to barter did relatively better in terms of output growth as compared to the economy as a whole. We take arrears as evidence that the firm faced a liquidity constraint and therefore turned to other firms for credit. ${ }^{13}$

\footnotetext{
${ }^{12}$ Note that this empirical prediction also holds if barter does not involve a credit relationship but if the goods used as payment are available right away.

${ }^{13}$ Marin, Kaufmann and Gorochowskij (1999) provide evidence that arrears can indeed be taken as a measure for the credit constraint. They show that inter-enterprise credit is negatively associated with bank credit for private firms. They infer from this negative association between these two types of credit that inter-firm credit cushioned the liquidity contraction induced by lower bank credit. For another
} 
Insert Table 1 here

We measure the relative growth performance of the firm by the mean percentage deviation of the output growth of the firm between 1994 and 1996 relative to GDP growth in the Ukraine in the same period. The table shows that the firms of our sample experienced the same growth rate as GDP of the Ukraine economy. However, firms with total arrears of more than 25 percent of output did substantially better in terms of output than firms with total arrears of less than 25 percent. When total arrears are decomposed into tax, wage and firm arrears, a slightly different picture emerges for wage and firm arrears. When wage and firm arrears become very large (over 9 percent and over 50 percent of output, respectively) then the firm's output performance becomes worse than that of the economy as a whole.

A similar picture emerges for the firm's barter exposure. Firms with a barter share of output over 70 percent did less well and those with a barter share of over 30 percent performed better compared to the economy as a whole. The data seem to confirm the inversely U-shaped behavior between output growth on the one hand and firm arrears and barter on the other.

In order to explore this relationship in more detail we regressed the relative output growth of the firm on BK's index of complexity, total arrears, and the barter share of the firm. The results are reported in Table 2. Column 1 reports the result of a regression that includes only BK's index of complexity. BK use the complexity variable as a measure for the severity of the hold-up problem. Complexity is an index that takes the value of zero if the sector uses only one input and approaches one when the sector uses several inputs from other sectors. We matched the ISIC sector of our bartering firms with the sector of the complexity index given by BK. The measure of complexity is constructed on the basis of the 1990 "100-sector" input-output table for Russia. We use this variable for the Ukraine, since both economies have very similar input-ouput structures. The ISIC classification of our sample could not always be perfectly matched with BK's classification of the index which might have introduced some noise into the complexity measure.

explanation of arrears in Russia see Rostowski (1993). 
Insert Table 2 here

The variable is negative and highly significant, which confirms BK's results. ${ }^{14}$ How- $^{-}$ ever, as equations (8) and (9) of Proposition 1 show, the degree of complexity (the number of production steps $n$ ) worsens both the hold-up problem as well as the credit problem. Thus, the estimated effect of complexity on output growth might be due to the fact that firms are short of cash and face a credit constraint rather than due to the fact that they have no trust in their business partners. In order to distinguish between the two problems we introduce total arrears of the firm into the equation as a proxy for the firm's credit constraint (column 2-6). ${ }^{15}$ Arrears can be seen as a proxy for the credit enforcement costs $\mathrm{x}$ which increase with the firm's indebtedness. As expected, the arrears variable has a positive sign and is highly significant. The positive sign suggests that indeed the credit constraint enables the firm to deal with specificity.

Next, we include the firms' barter share into the equation (column 4). The variable turns out to have a negative and significant effect on output growth. We also include a quadratic term of the barter share into the equation to capture the inversely U-shaped relationship between output growth and barter which is significant and positive.

In order to look at the inversely U-shaped relationship between arrears and barter on the one hand and output growth on the other in more detail, we divided the data into the following subsamples: high barter firms with a barter share of over 70 percent, low barter firms with a barter share of less than 30 percent, and high debt firms with total arrears of more than 40 percent of output. We also look at those firms in the sample which performed better than the economy as a whole. Consider first the results for the two barter subsamples which are given in columns 7 to 14 of Table 2. The regressions indeed give a positive effect of barter on output growth for low barter firms and a negative one for high barter firms. It is interesting to note that for the sample of low barter firms the inclusion of the arrears variable in the equation reduces the estimated effect of complexity on output substantially and the effect becomes insignificant at conventional levels. Apparently, for

\footnotetext{
${ }^{14}$ Note that Konings and Walsh (1999) instead find that disorganization did not constrain employment and productivity growth in newly established private firms in the Ukraine.

${ }^{15}$ Ickes and Ryterman (1993) also see arrears in Russia as a response to a liquidity shortage in the economy.
} 
these firms the complexity variable seems to be capturing more of a financial shortage than that of an input shortage.

Consider next the results for the sample of high arrears firms given in columns 15 to 18. For highly indebted firms arrears do not appear to play a role for output growth. These firms appear to have too large credit enforcement costs to make it worthwhile for the input supplier to participate in the deal. Moreover, these firms seem to be so little creditworthy that even barter cannot help them to maintain production by getting trade credits from other firms.

The results for the sample of high growth firms are given in columns 19 to 22 . It appears that these firms showed a favorable growth performance because they used their credit constraint and barter activity effectively to avoid an input and financial shortage.

Finally, we include the share of bank debt in percent of the firm's output in the output growth regressions given in columns $6,10,14,18$, and 22 of Table 2 . This is an alternative way to capture whether or not firms faced a credit contraction problem. The positive and significant coefficient of the share of bank debt supports Calvo and Coricelli's view that credit contraction and the associated liquidity shortage have caused the output decline in Eastern Europe. ${ }^{16}$

\section{$5 \quad$ Evidence on Specificity and Credit Constraints with Deal-Specific Data}

In this section we turn to the deal specific predictions of our model which we would like to test. We need to evaluate how the hold-up problem and the credit constraint specified in the previous sections are reflected in the terms of the barter contract. We have argued above that the hold-up problem can be alleviated if the input buyer faces a credit constraint and that barter is used if credit enforcement becomes too costly for

\footnotetext{
${ }^{16}$ Calvo and Coricelli run a similar regression between output and credit for Poland. They get a point estimate between 0.2 and 0.6 depending on specification which suggests that a 10 percent contraction of credit results in an output decline between 2 and 6 percent. Note further that BK report evidence based on a survey among 500 firms in Russia which suggests that the financial constraint was the most important shortage experienced by enterprises (see their Table IV). Between 1993 and 1995 over 60 percent of the firms experienced a shortage of financial resources compared with only over 20 percent of the firms experiencing shortages of material.
} 
the seller. Thus, we expect these problems to be reflected in the prices chosen in barter contracts as compared to the prices in cash deals where no such problems are present.

Recall from equation (2) that the price chosen for the input good in barter is equal to

$$
p_{1}=\min \left[\frac{v_{1}}{2}+x ; v_{1}\right] .
$$

Compare this price with the usual cash price for the input good with no such problems. In this case the investment costs $i$ can be contracted on before investment takes place, and the buyer has no liquidity constraint and thus cannot use it to renegotiate the input price. Splitting of the surplus implies a cash price $p_{1}^{C}$

$$
p_{1}^{C}-i=v_{1}-p_{1}^{C} \quad \leftrightarrow \quad p_{1}^{C}=\frac{v_{1}-i}{2} .
$$

Thus, $p_{1}^{C}=\frac{v_{1}-i}{2}<\min \left[\frac{v_{1}}{2}+x ; v_{1}\right]=p_{1}$ because the cash price reflects the investment cost $i$ and does not include a mark-up for the credit enforcement cost $x$.

Similarly, if $p_{1}$ cannot be increased anymore because it reaches its upper bound $v_{1}$, then we expect a discount on $p_{B}$ as compared to the cash price $p_{B}^{C}$, as specified in equation (14) given below

$$
p_{1}=\frac{v_{1}}{2}+x-\left(\frac{w+k}{2}-p_{B}\right)=\frac{v_{1}}{2}+x-\left(p_{B}^{C}-p_{B}\right)
$$

Thus, we expect that the hold-up problem and the credit problem both shift the terms of trade of the barter contract in favor of the input supplier, either by an increase of $p_{1}$ as compared to $p_{1}^{C}$ or by a decrease of $p_{B}$ as compared to $p_{B}^{C}$ or both.

Our model predicts further that the price discount on the barter good will be larger the larger the hostage $z$, i.e. the smaller $\pi$ and the larger $(w-k) / 2$, as can be seen in equations (15) and (16). Thus, the more specific (the smaller $\pi$ ) and the more liquid (the larger $(w-k) / 2)$ the barter good the larger the discount on $p_{B}$ and thus the more shifts the terms of trade in favour of the input supplier.

To measure the shift of the terms of trade in barter relative to the prices prevalent in cash transactions we use the variable TOT. TOT is defined as the difference of SCASH and PCASH, where SCASH and PCASH are the percentage differences of barter prices as compared to cash prices for the input good and the barter good, respectively. Let $p_{1}^{C}$ 
and $p_{1}$ denote the price for the input good in cash and barter transactions, respectively. Similarly, let the price for the barter good in cash and in barter transactions be $p_{B}^{C}$ and $p_{B}$. Thus, the percentage price change for the input good is $\left(p_{1}-p_{1}^{C}\right) / p_{1}^{C}$ and the percentage price change for the barter good is $\left(p_{B}-p_{B}^{C}\right) / p_{B}^{C}$. The net terms of trade effect is measured by $\mathrm{TOT}=\mathrm{SCASH}-\mathrm{PCASH}$.

In order to obtain a proxy for the severity of the hold up problem (a measure for $n$ ) on the input deal we have classified the input good and the barter good of each transaction according to the complexity index given by BK. With this method we constructed a dealspecific complexity measure for both goods exchanged, SCOMPLEX and PCOMPLEX. Furthermore, we use as a proxy for the creditworthiness (as a measure for $\mathrm{x}$ ) of the input purchaser her total outstanding debt (firm arrears, wage arrears and tax arrears), PARREARS. The data allow us to distinguish whether the firm is on the selling or buying end of the transaction.

Insert Table 3 here

We first look at the price effect on each of the deals separately and then in a next step focus on the net effect on the terms of trade of both transactions together. Consider first the regression on the percentage price change on the input deal SCASH given in columns 1 to 7 in Table 3. The more complex the input good the more severe is the hold-up problem in the input deal and thus the larger the barter price $p_{1}$ relative to the cash price $p_{1}^{C}$. Thus we expect a positive sign on the complexity index for the input good SCOMPLEX. This is supported by the regressions. The input specific complexity measure is positive and significant independent of the specification. ${ }^{17}$

Furthermore, we expect the input purchaser's indebtedness (PARREARS) to have a positive effect on SCASH, since the input seller will inflate the barter input price $p_{1}$ relative to the cash price $p_{1}^{C}$ to cover the anticipated credit enforcement costs $x$. The

\footnotetext{
${ }^{17}$ These empirical findings justify the assumption we made in the model that the hold-up problem arises on the buyer's rather than on the seller's side. If BK's formulation of the hold-up problem on the seller's side were valid the input price would be lower rather than higher in barter as compared to cash deals. Thus, in this case we would have expected a negative rather than a positive coefficient on the complexity index.
} 
coefficient on PARREARS is zero and insignificant suggesting that the input supplier has not been able to pass on these costs on the input purchaser. Our theory predicts for this case that the input purchaser will need to shift some of the profit back to the input supplier in order to make him participate in the deal by discounting the price for the barter good. Thus, we expect a negative sign on the PARREARS variable in the regressions for PCASH. Looking at the regression results for the percentage price change on the barter good PCASH given in columns 8 to 14 this is indeed confirmed by the data. PARREARS is negative and highly significant.

Consider next the net terms of trade effect of both transactions given in columns 15 to 22 of Table 3. We expect a positive sign for SCOMPLEX and PARREARS in the TOT regressions, since a larger SCASH due to the hold-up problem and a smaller PCASH due to the credit problem imply both a larger TOT. This is indeed the case. The data suggest then that the hold-up problem is reflected in an inflated price on the input deal and the input purchaser's credit problem appears to have been so severe that it had to be taken care of by price concessions on the barter side of the contract. Both problems have shifted the terms of trade in favour of the input seller.

We predict two more variables to have affected the terms of the contract: the liquidity $w$ and the anonymity $\pi$ of the barter good. The more liquid and the less anonymous the barter good, the larger the hostage value of barter and thus the larger the discount on the price of the barter good $p_{B}$ relative to the cash price $p_{B}^{C}$. Thus, we expect a negative coefficient of liquidity and anonymity in the PCASH regressions and a positive coefficient for the same variables in the TOT regressions.

We measure the liquidity and anonymity of the barter good by PCOKE and PCOMPLEX. ${ }^{18}$ PCOKE is a dummy variable taking the value of one if the barter good is coke or petroleum. Coke is a liquid good (everybody uses it for heating) which can be sold easily on the market at a known price. PCOMPLEX measures the complexity of the barter good. We use it as a proxy for the degree of specificity of the barter good. If the complexity index for the barter good is large and thus there are many production steps to get from the raw input to the final good, we infer that the barter good can be potentially

\footnotetext{
${ }^{18}$ For the concept of liquidity in an incentive theory of money see Banerjee and Maskin (1997); see Marin and Schnitzer (1997) who use the liquidity and anonymity properties of goods to explain the trade pattern of barter in international trade.
} 
used only by a small number of firms. The more specific the good is for the creditor's use, the harder it will be for the debtor to cheat on repayment and to sell the good to someone else than the creditor. We therefore expect a negative coefficient on PCOMPLEX in the PCASH regressions and a positive coefficient in the TOT regressions.

Turning to the results given in Table 3 PCOKE has the wrong sign but is not significant. PCOMPLEX has the expected sign and is highly significant in all regressions.

Additionally, we include the variables SSTATE and PDISTORT to control for other distortions in the economy which might have influenced the terms of the contract. SSTATE is a dummy variable taking the value of one if the selling firm is a state owned enterprise. PDISTORT is a dummy of value one if the market for the barter good is regulated and thus $p_{B}^{C}$ does not reflect market forces. It appears that when the seller is a state enterprise the input price is discounted and the barter price is inflated suggesting that the state firms subsidized their buyers. In contrast, when the price for the barter good is regulated, then the contract is used to shift the terms of trade in favour of the seller rather than the buyer.

Finally, we use the variables REPEAT and RELATION which capture the terms of the relationship between the input supplier and purchaser. RELATION is a dummy that takes the value of one if the seller is an energy or other input provider and zero otherwise. REPEAT is a dummy with the value of one if there is a history in the relationship between the input seller and the purchaser. RELATION measures the quality of the relationship and REPEAT the duration of the relationship between the parties. We expect both variables to have enhanced trust among the parties involved in the deal and thus to have an impact on the terms of the contract. Both variables are, however, not significant in any of the regressions. In times of historic change, reputation does not appear to have governed the behaviour of the parties.

\section{Conclusion}

In this paper we establish a link between the output decline, inter-firm arrears, and barter in the former Soviet Union. We show that inter-firm arrears can be used by firms to avoid the problems associated with complexity and specificity. The fact that input suppliers 
have to worry about being paid when they extend trade credits to their buyers means that they cannot exploit their buyers' dependence on these inputs. This way, the presence of arrears has helped to avoid the output to collapse even more than it actually has in the former Soviet Union.

However, very large arrears become counterproductive for maintaining production because credit enforcement becomes very costly and thus input suppliers will refuse to extend credit to their buyers. Under these circumstances, barter trade is the only way to maintain production. Barter trade is an inter-firm credit which is repaid in goods rather than money. Barter creates a hostage which can be used to collateralize a trade credit when firms' creditworthiness problem is severe. This function of barter explains why firms are able to give loans to each other when the banking sector is reluctant to provide capital.

Our model is able to explain the pattern of arrears and barter over time and across transition economies. The arrears crisis started in 1992 - 19993 in Russia, reaching almost 10 percent of GDP (firm and tax arrears) while barter started to rise in 1994. The theory predicts barter to exist when arrears reach a critical level at which credit enforcement becomes so costly that firms refuse to extend further trade credits to each other and thus only barter can maintain production. Our data suggest that arrears reached this crititcal level at around 30 to 40 percent of firms' sales. Thus, we argue that the explosive increase of barter in Russia since 1994 (from 5 percent of sales in 1993 to around 60 percent of sales in 1998) has been triggered by a level of arrears at which production was unsustainable.

Furthermore, the model provides an explanation for why the former Soviet Union differs from the early transition economies in Central Europe. Disorganization and specificity have posed a more severe problem for more insulated economies like the former Soviet Union, while in open economies like Central Europe entry of foreign firms alleviated the problems of small numbers. This is why the output fall was more pronounced in the former compared to the latter. In the former Soviet Union other mechanisms than international trade and foreign direct investment must have been at work to limit the adverse effect of specificity. We argue in this paper that inter-firm arrears and barter can be seen as such mechanisms to deal with problems arising in the transition. Inter-firm arrears are larger and growing faster in the former Soviet Union compared to Central Europe because of their role to deal with disorganization and hold-up. Barter is observed in 
the former Soviet Union while being absent in Eastern Europe because the arrears crisis was more severe in the former than the latter region.

Our model has an important implication for the effectiveness of monetary policy in the former Soviet Union. In Russia's barter economy a monetary expansion has perverse effects. The reason is that reducing arrears by fusing liquidity into the economy will eliminate input buyers' bargaining power thereby robbing them of their instrument to deal with disorganization and the trust problem of the economy. This leads to less rather than more output. Thus, in a distorted economy like Russia's eliminating one distortion - arrears through a monetary expansion - without removing the other distortion - the trust problem in the economy - will not lead to desired outcomes. Monetary policy will lead either to lower output, because production breaks down due to the hold-up problem, or to higher inflation, because input suppliers will inflate their inputs to exploit their bargaining power when the hold-up problem is not too large. In other words, a monetary expansion in a barter economy works like introducing partial reform in an overall distorted economy. ${ }^{19}$

\footnotetext{
${ }^{19}$ For the argument why partial reform might make things worse in an overall distorted economy see Murphy, Shleifer and Vishny (1992).
} 


\section{Appendix}

\section{Proof of Lemma 1:}

Suppose that all buyers are liquidity constrained and thus have to delay repayment. Consider now the final step of production. This is exactly like the first step, with the only exception that $B_{n}$ does not have to make an up-front investment. Then the two parties share the joint surplus as follows: $S_{n}$ receives $p_{n}-x=v / 2$ and $B_{n}$ receives $v-p_{n}+x=v / 2$, provided $x \leq v / 2$. If $v / 2<x<v$, then $B_{n}$ receives $x$ and $S_{n}$ receives $v-x$. If $x \geq v$, then no production takes place at the final step. The value of production at step $n-1$ is equal to the payoff of the seller at the last production step. Solving the game recursively this leads to the following value of production at step $j, j=1, \ldots, n-1$

$$
v_{j}= \begin{cases}\frac{v}{2^{n-3}} & \text { if } x \leq \frac{v}{2^{n-j}} \\ \frac{v}{2^{n-j-1}}-x & \text { if } \frac{v}{2^{n-j}}<x<\frac{v}{2^{n-j-1}} \\ 0 & \text { if } \frac{v}{2^{n-j-1}} \leq x\end{cases}
$$

Note that if $x>\frac{v}{2^{n-j-1}}$ production will not take place at step $j+1$ because the seller $S_{j+1}$ will not be able to guarantee himself a positive payoff. Thus, the value of production at step $j$ is zero.

Q.E.D.

$\underline{\text { Proof of Proposition } 1}$

Production takes place if and only equations (6) and (7) are satisfied.

(i) If $x=0$, equation (6) is satisfied by assumption and (7) is satisfied if and only if $i \leq v / 2^{n}$.

(ii) If $i=0$, equation (7) is satisfied by assumption and (6) is satisfied if and only if $x<v / 2^{n-1}$.

(iii) Suppose $i>0$ and $x>0$. If $x \leq v / 2^{n}$, then (6) is satisfied by assumption and and (7) is satisfied if and only if $i \leq v / 2^{n}$. If $v / 2^{n}<x<v / 2^{n-1}$, then (6) is satisfied by assumption and and (7) is satisfied if and only if $i \leq x$. If $x>v / 2^{n-1}$, then (6) is violated and no production takes place.

Q.E.D. 


\section{Proof of Proposition 2}

Note first that we can determine the value of $v_{1}$, just like in Lemma 1 , with the only difference that now the enforcement cost $x$ are reduced by the hostage $z$. Of course, barter needs to take place only at those production steps $j$, where $x>v_{j} / 2$, i.e. the liquidity constraint prevents an equal sharing of the surplus at production stage $j$. With this in mind, we can solve the game recursively as done in Lemma 1, with the only difference that now instead of $x$ we have to consider $x-z$, whenever $x$ is hitting this constraint.

Thus, we have $v_{1}(x, z)=\frac{v}{2^{n-1}}$ if $x-z \leq \frac{v}{2^{n-1}}$ and $v_{1}(x, z)<\frac{v}{2^{n-1}}$ if $x-z>\frac{v}{2^{n-1}}$.

Recall that $p_{1}$ and $p_{B}$ are fixed such that the parties share the surplus equally whenever possible. This implies to set

$$
p_{B}=\frac{w+k}{2}-z
$$

which allows in turn to set

$$
p_{1}=\min \left[\frac{v_{1}}{2}+x-z ; v_{1}\right]
$$

Note that both $S_{1}$ and $B_{1}$ need to be willing to participate and make the necessary investment. This requires for $B_{1}$ that

$$
v_{1}-\left(p_{1}-x\right)+p_{B}-k-i \leq \frac{w-k}{2}
$$

and for $S_{1}$ it requires

$$
\left(p_{1}-x\right)+w-p_{B}>\frac{w-k}{2} .
$$

Suppose $x-z<\frac{v}{2^{n-1}}$. Then $v_{1}=\frac{v}{2^{n-1}}$. Suppose furthermore that $x-z<\frac{v}{2^{n}}=\frac{v_{1}}{2}$. Then, using the equations for $p_{1}$ and $p_{B},(27)$ requires that

$$
\frac{v_{1}}{2}=\frac{v}{2^{n}} \geq i
$$

and (28) requires that

$$
\frac{v_{1}}{2}=\frac{v}{2^{n}}>0
$$

Note that this is condition (19) in Proposition 2. 
Suppose next that $x-z<\frac{v}{2^{n-1}}$, so that $v_{1}=\frac{v}{2^{n-1}}$, but that $\frac{v}{2^{n}}=\frac{v_{1}}{2}<x-z<\frac{v}{2^{n-1}}=$ $v_{1}$. Then, using the equations for $p_{1}$ and $p_{B},(27)$ requires that

$$
x-z \geq i
$$

and (28) requires that

$$
v_{1}=\frac{v}{2^{n-1}}>x-z
$$

Note that this is condition (20) in Proposition 2.

Finally, note that if $x-z>\frac{v}{2^{n-1}}$, then $v_{1}<\frac{v}{2^{n-1}}$ and it is not possible to satisfy (28) so that no production takes place as specified in Proposition 2.

Q.E.D. 


\section{References}

BAnerJee, Abijit AND ERIC Maskin, "A Walrasian Theory of Money and Barter" Quarterly Journal of Economics 1996, 111, 955-1005.

Blanchard, Olivier and Michael Kremer, "Disorganization", Quarterly Journal of Economics, 1997, 112, 1091-1126.

Calvo, Guillermo A. and Fabrizio Coricelli, "Inter-enterprise Arrears in Economies in Transition", in Holzmann Robert et al. (eds.): Output Decline in Eastern Europe, 1995a, Dordrecht: Kluwer Academic Publishers.

Calvo, Guillermo A. And Fabrizio Coricelli, "Output Collapse in Eastern Europe: The Role of Credit", in M.I. Blejer, Calvo G., Coricelli F. and A. Gelb (eds.): Eastern Europe in Transition: From Recession to Growth? World Bank Discussion Paper 196, World Bank, Washington 1995b.

Commander, Simon and Christian Mumssen, "Understanding Barter in Russia" European Bank for Reconstruction and Development, 1998, mimeo, London.

Ellingson, Tore, "Payments in Kind", 1998, mimeo, Stockholm.

ICKES, BARRY W. AND RANDi RYTERMAn, "Roadblock to Economic Reform: InterEnterprise Debt and the Transition to Markets", Post-Soviet Affairs, 1993, 9, 231-252.

Konings, Jozef and Patrick Paul Walsh, "Disorganization in the Transition Process: Firm-level Evidence from Ukraine", Economics of Transition 1999, 7, 29-46.

Marin, Dalia, Kaufmann Daniel and Bogdan Gorochowskij, "Barter in Transition Economies: Competing Explanations Confront Ukrainian Data", University of Munich, The World Bank, Humboldt University Berlin, mimeo, 1999.

Marin, Dalia And Monika Schnitzer, "Tying Trade Flows: A Theory of Countertrade with Evidence", American Economic Review, 1995, 85, 1047-1064.

Marin, Dalia AND Monika Schnitzer, "The Economic Institution of International Barter", CEPR Discussion Paper No 1658, London, 1997.

Murphy, Kevin M., Andrei Shleifer and Robert W. Vishny, "The Transition to a Market Economy: Pitfalls of Partial Reform", Quarterly Journal of Economics, 1992, 107, 889-906.

Prendergast, Canice and Lars Stole, "Barter, liquidity and market segmentation" 1997, mimeo, University of Chicago.

Roland, Gerard And Thierry Verdier, "Transition and the Output Fall", Economics of Transition 1999, 7, 1-28.

Rostowski, JACEK, "The Inter-Enterprise Debt Explosion in the Former Soviet Union: Causes and Consequences, Cures", Center for Economic Performance/ESR Discussion Paper No 142, 1993. 
Russian Economic Barometer, Survey of Industrial Firms, Institute for World Economy and International Relations, Moscow, 1997.

Transition Report, European Bank for Reconstruction and Development, London, 1997.

Transition Report, European Bank for Reconstruction and Development, London, 1998. 
Definition of Variables and Sample Statistics

\begin{tabular}{|c|c|c|c|c|c|c|}
\hline Variable & Observations & Description & Mean & Min. & Max. & Std Dev. \\
\hline arrears & 138 & $\begin{array}{l}\text { share of firm's arrears (tax, wage } \\
\text { and firm arrears) in percent of } \\
\text { output }\end{array}$ & 41.40 & 1.00 & 687.90 & 101.068 \\
\hline parrears & 69 & $\begin{array}{l}\text { total arrears of purchasing firm in } \\
\text { percent of output }\end{array}$ & 65.30 & 0.00 & 687.90 & 157.947 \\
\hline bankdebt & 150 & $\begin{array}{l}\text { firm's bank debt in percent of } \\
\text { output }\end{array}$ & 6.31 & 0.00 & 104.20 & 15.955 \\
\hline tax arrears & 150 & $\begin{array}{l}\text { firm's tax arrears in percent of } \\
\text { output }\end{array}$ & 7.15 & 0.00 & 121.50 & 19.306 \\
\hline wage arrears & 150 & $\begin{array}{l}\text { firm's wage arrears in percent of } \\
\text { output }\end{array}$ & 3.38 & 0.00 & 38.60 & 6.001 \\
\hline firm arrears & 138 & $\begin{array}{l}\text { firm's inter-firm arrears in percent } \\
\text { of output }\end{array}$ & 30.15 & 0.70 & 626.00 & 90.887 \\
\hline $\begin{array}{l}\text { relative firm } \\
\text { growth }\end{array}$ & 153 & $\begin{array}{l}\text { percentage deviation of firm's out- } \\
\text { put growth relative to the growth } \\
\text { rate of GDP between } 1994 \text { and } 1996\end{array}$ & 0.01 & -2.03 & 25.43 & 4.215 \\
\hline barter & 165 & $\begin{array}{l}\text { share of firm's barter in percent of } \\
\text { output }\end{array}$ & 45.21 & 1.00 & 100.00 & 28.181 \\
\hline complexity & 141 & $\begin{array}{l}\text { complexity index of the industrial } \\
\text { sector of the firm; the index is equal } \\
\text { to zero if there is only one input and } \\
\text { tends to one if the sector uses many } \\
\text { inputs. }\end{array}$ & 0.80 & 0.34 & 0.92 & 0.116 \\
\hline scomplex & 142 & $\begin{array}{l}\text { complexity of input good; the index } \\
\text { is equal to zero if there is only one } \\
\text { input and tends to one if input good } \\
\text { is produced with many inputs }\end{array}$ & 0.77 & 0.30 & 0.92 & 0.139 \\
\hline pcomplex & 145 & $\begin{array}{l}\text { complexity of barter good; the in- } \\
\text { dex is equal to zero if there is only } \\
\text { one input and tends to one if barter } \\
\text { good is produced with many inputs. }\end{array}$ & 0.75 & 0.19 & 0.92 & 0.134 \\
\hline
\end{tabular}


Definition of Variables and Sample Statistics Continued

\begin{tabular}{|c|c|c|c|c|c|c|}
\hline Variable & Observations & Description & Mean & Min. & Max. & Std Dev. \\
\hline tot & 163 & $\begin{array}{l}\text { net difference between cash and } \\
\text { barter price in percent (scash- } \\
\text { pcash) }\end{array}$ & 4.59 & -168.00 & 50.00 & 18.075 \\
\hline scash & 163 & $\begin{array}{l}\text { difference between the barter price } \\
\text { and cash price in percent of the cash } \\
\text { price for the input good }\end{array}$ & 3.43 & -16.70 & 49.00 & 8.302 \\
\hline pcash & 163 & $\begin{array}{l}\text { difference between the barter price } \\
\text { and cash price in percent of the cash } \\
\text { price for the barter good }\end{array}$ & -1.16 & -50.00 & 186.00 & 18.633 \\
\hline sstate & 165 & $\begin{array}{l}\text { dummy variable equal to one if sell- } \\
\text { ing firm is state } \\
\text { owned }\end{array}$ & \multicolumn{4}{|c|}{$\mathrm{D}=1,49$ observations } \\
\hline pdistort & 165 & $\begin{array}{l}\text { dummy variable equal to one if mar- } \\
\text { ket for barter good is regulated }\end{array}$ & \multicolumn{4}{|c|}{$\mathrm{D}=1,36$ observations } \\
\hline pcoke & 148 & $\begin{array}{l}\text { dummy variable equal to one if } \\
\text { barter good is coke or } \\
\text { petroleum }\end{array}$ & \multicolumn{4}{|c|}{$\mathrm{D}=1,16$ observations } \\
\hline relation & 164 & $\begin{array}{l}\text { dummy variable equal to } 1 \text { if seller } \\
\text { is input supplier }\end{array}$ & \multicolumn{4}{|c|}{$\mathrm{D}=1,88$ observations } \\
\hline repeat & 165 & $\begin{array}{l}\text { dummy variable equal to } 1 \text { if } \\
\text { seller and buyer have interacted } \\
\text { frequently }\end{array}$ & \multicolumn{4}{|c|}{$\mathrm{D}=1,87$ observations } \\
\hline
\end{tabular}




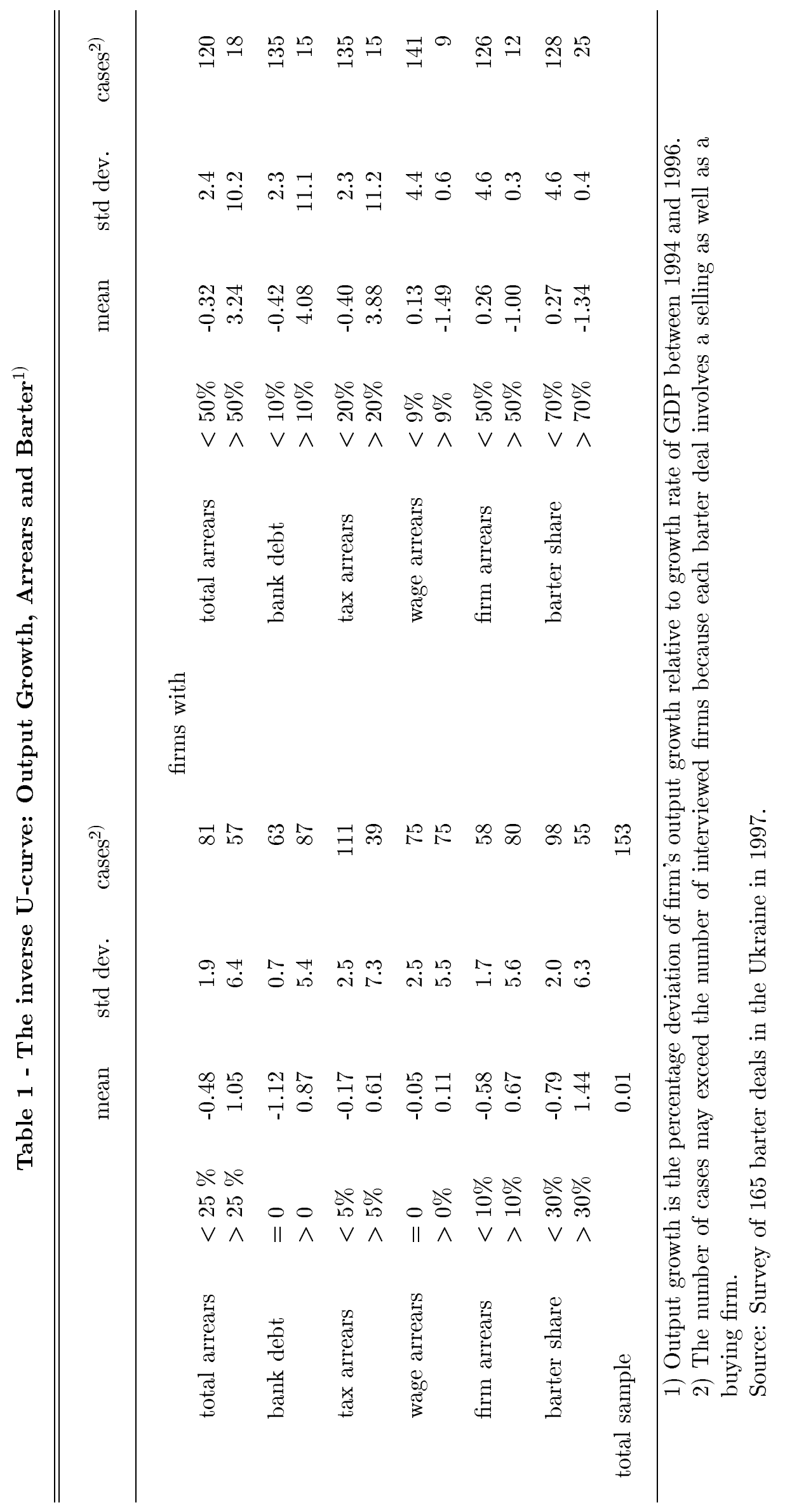




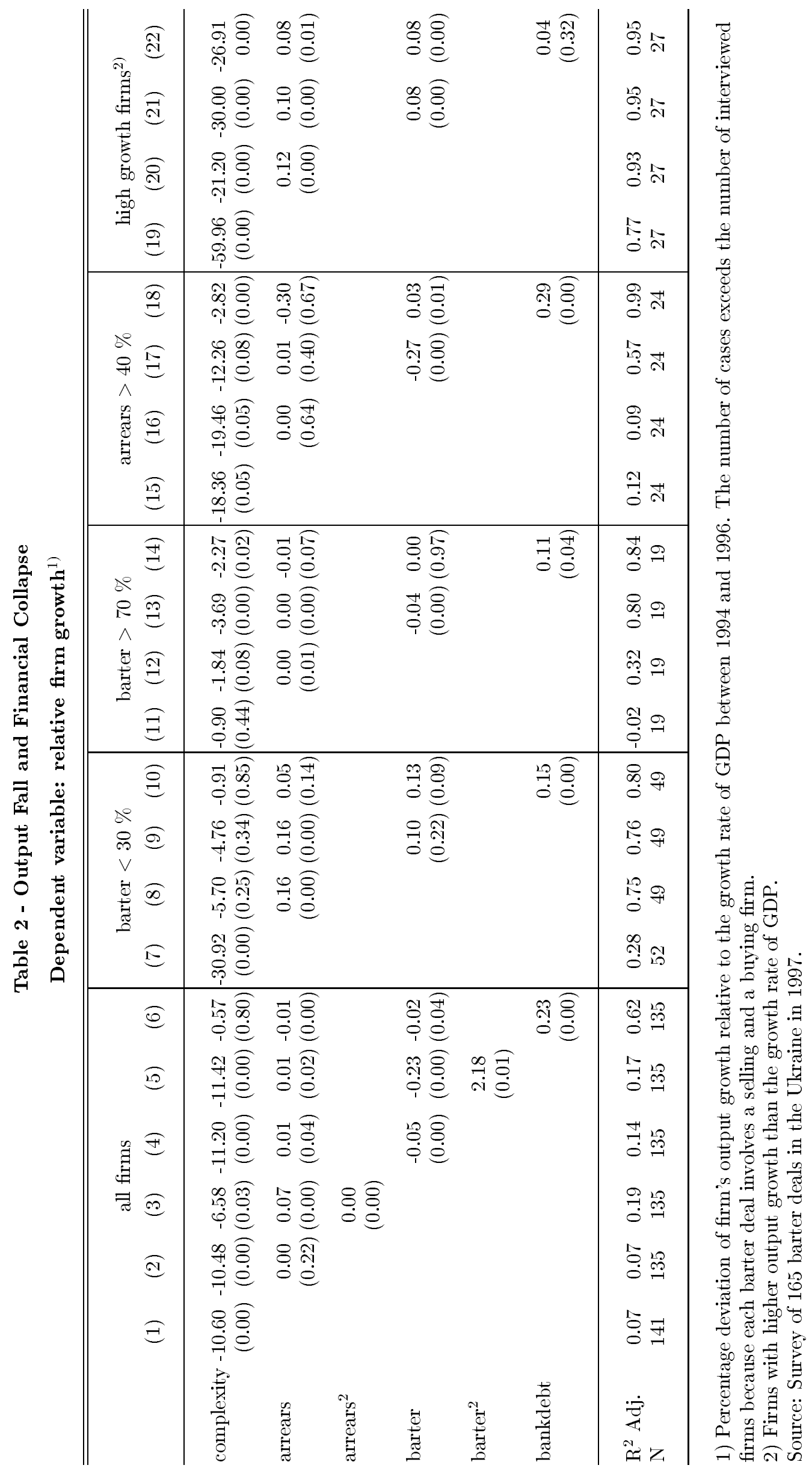




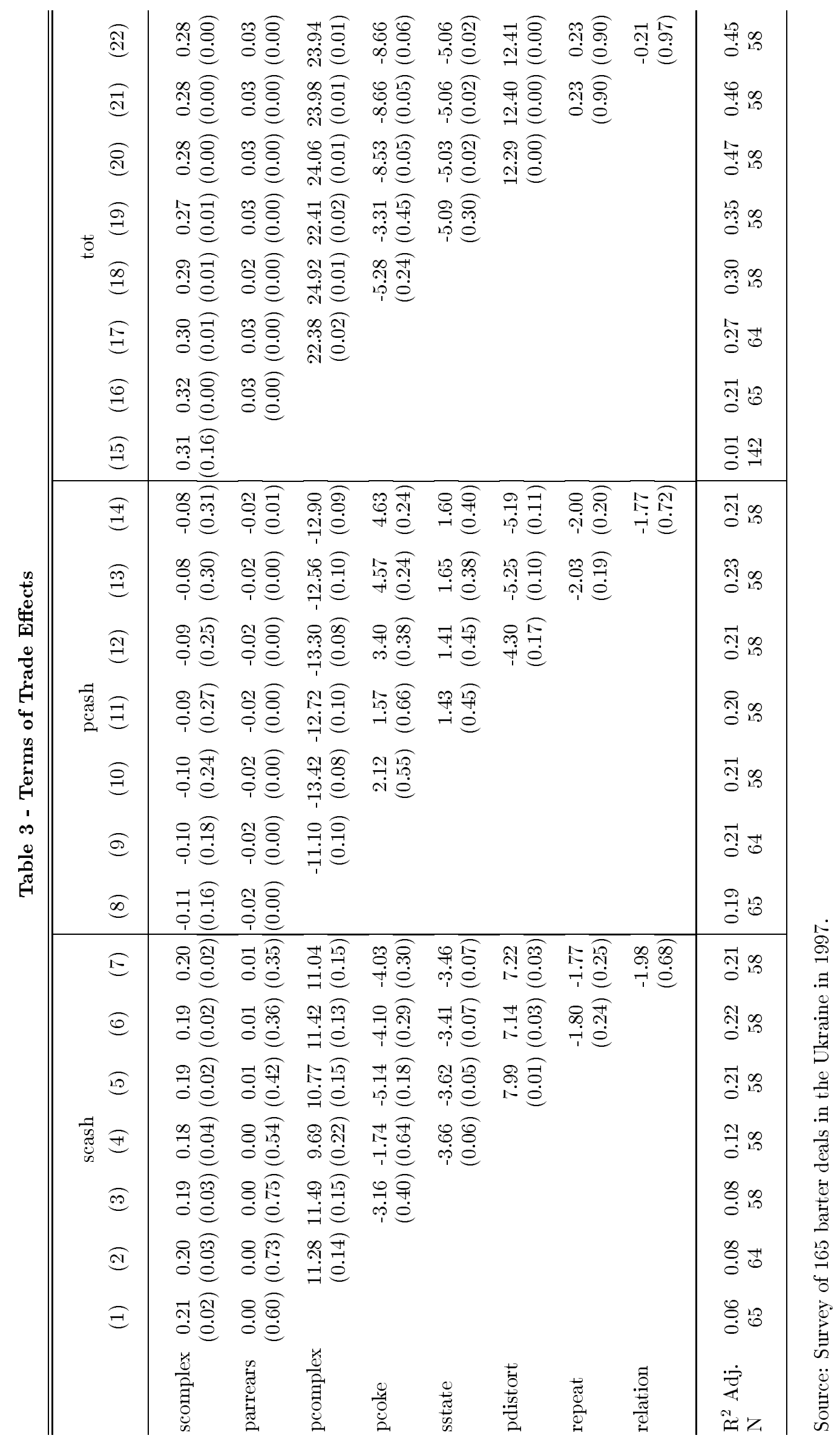

